\title{
Comparison between the circular and square collar in reduction of local scouring around bridge piers
}

\author{
Saeed Reza Khodashenas ${ }^{1, *}$, Hossain Shariati ${ }^{2}$, Kazem Esmaeeli $^{3}$ \\ 1,2,3 Water Engineering Department, Ferdowsi University of Mashhad, Iran
}

\begin{abstract}
In this study operation of two types of circular and square collars has been investigated on a single cylindrical pier. The results showed that using of these two types of collars cause to reduction of scour depth especially under the bed level (elevation). This research showed that the square collar is more effective than circular shape in decreasing of the scour depth). The square and circular collars showed $70 \%$ and $50 \%$ decrease in rate of scour depth, respectively in compared with simple pier without collar.
\end{abstract}

\section{Introduction}

Flow pattern and mechanism of scouring around a bridge pier is very complex and has been reported by various investigators. Local scouring around the bridges pier occurs because of flow separation and developing several vortexes around the bridge pier (Fig 1). Different methods have been proposed to prevent or reduce scouring around bridge piers (as riprap, submerged plates, slots, and collars). Generally scour reduction methods divide to two categories: direct methods and indirect methods. The first methods use to increase the bed resistance and second methods use to change the flow pattern around the bridge piers

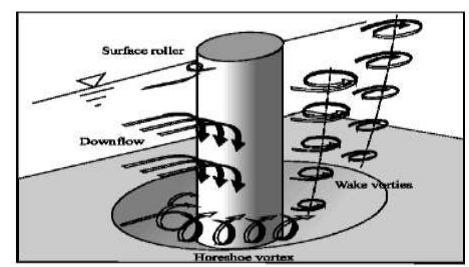

Fig. 1. Illustration of the flow and scour pattern at a circular pier [1].

Melville and Coleman [1] defined collars as devices attached to the pier at some levels usually close to the bed. A collar is in the form of a thin protective disc. A collar extends around the outside edge of the pier with the main objective of protecting the bed from the scouring effect of the down-flow at the associated vortex action around the base of the pier. The concept behind using collar is that it will sufficiently deflect the down-flow vortex which results reduction of scour hole by reducing the strength of down-flow and horse-shoe vortices. (Fig. 2).

\footnotetext{
* Corresponding author: khodashenas@ferdowsi.um.ac.ir
} 


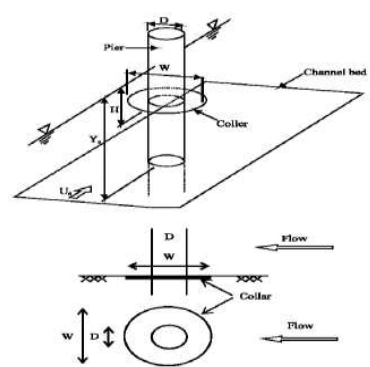

Fig. 2. Collars positioned around circular pier ([2])

Kumar et.al [3] investigated "Reduction of local scour around bridge piers using slots and collars. Their studies showed that as the collar size is bigger, it has more effect on reduction of scour damage. Zarrati et.al [4] investigated the effect of the collar at rectangular piers. They found that wider collar at lower elevation would be more effective. Also the efficiency of collar decreases by increasing of locating angle of the pier into the flow. Moncada et.al [5] investigated operation of collar and slot in scour reduction. Their results showed that using of 2D collar (D: pier diameter) can reduce scouring 55-96 percent. Brandimarte et al. [6] offered a broad review of the main aspects to be taken into account when analysing bridge pier scour: processes; measurements and estimate. Karimi et al. [7] examined the effect of bridge pier inclination angle on the scouring process by conducting tests along a straight channel in a Plexiglas laboratory flume. Their results showed that the maximum and minimum scouring depths occurred at pier angles of 0 and 15 respectively.

The aim of this study is investigation of collar application with different shape (square and circular), around the cylindrical pier at different elevations into the bed.

\section{Materials and methods}

Experiments were carried out at the hydraulic laboratory of Ferdowsi University of Mashhad, Iran. The flume long, width and height were 10, 0.3 and 0.5 meter, respectively (Fig.3). Measurement of discharge was done by a rectangular sharp edge weir that installed and calibrated beforehand at the entrance of the flume. A sluice gate was installed (located) at the end of the flume to control the flow depth (to adjustment of the flow depth used from a sluice gate that installed at the end of the flume). To developing of the flow, completely, the working section of the flume had $1.5 \mathrm{~m}$ long and was located $5 \mathrm{~m}$ downstream from the flume inlet section.
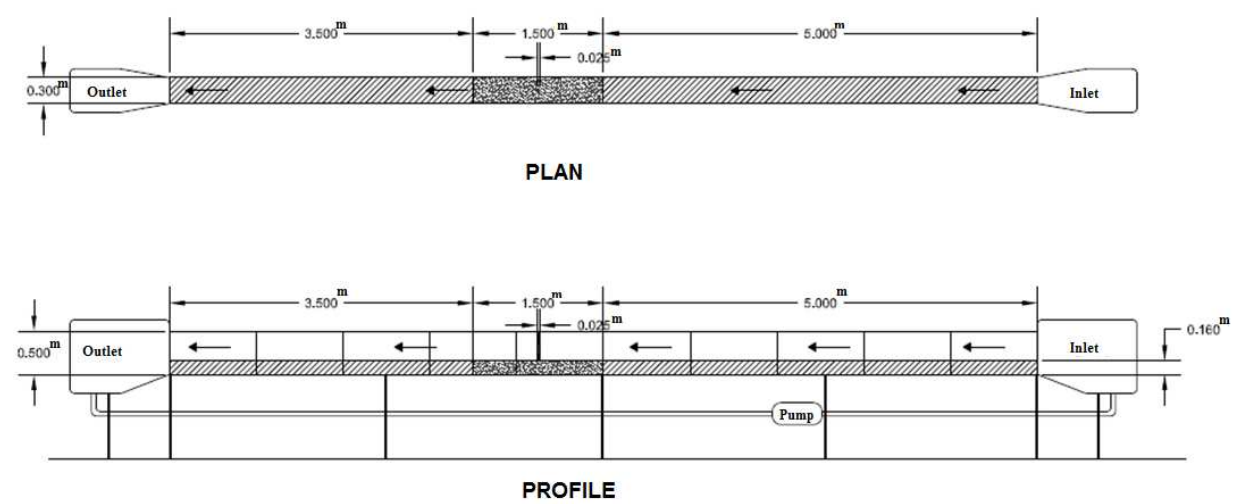

Fig. 3. Schematic view of laboratory flume 
The sediment thickness in working section was $0.16 \mathrm{~m}$ so the flume bed similarly was raised upstream and downstream of the working section. According to Chiew and Melville [8] to prevention of the sidewalls effect on the rate of scouring, the maximum diameter of pier should be $10 \%$ of flume width) and according to Raudkivi and Ettema [9] the flume width to the pier diameter ratio should be more than 6.25 and to prevention of the bed form creation (ripple) the median particle size $\left(\mathrm{d}_{50}\right)$ should be more than $0.7 \mathrm{~mm}$. Also to neglecting of the sediment effect on the scour depth, the pier diameter to the median particle size ratio should be more than 20-25D. Therefore a plastic cylindrical pier with $\mathrm{D}=25^{\mathrm{mm}}$ sediments with $-\mathrm{d}_{50}=0.8 \mathrm{~mm}$ was used (Fig. 5). If the ratio of flow depth to the pier diameter be more than 3.5, it doesn't have effect on the rate of scouring ([8]). Whereas the maximum local scour depth occurs in clear-water condition, at first by accomplishment of primary experiments and try and error, depth and discharge of the threshold of bed material motion selected $10.5 \mathrm{~cm}$ and $10 \mathrm{lit} / \mathrm{s}$ by Shields method and Melville equation, respectively as the threshold of motion condition that in this case $\left(U / U_{c}=0.9\right)$ (the flow velocity to critical velocity in threshold of motion ratio). To obtaining the equilibrium time and ending of each experiment, scour variations in simple pier section (witness pier) recorded about 15 hours into the time. The results showed that the rate of scouring was high at first and approximately $90 \%$ of scouring occurs at the first times (during the first hours). After 7 hours, the scour depth variations reduce significantly and at the eighth hour the scour depth reached to $1 \mathrm{~mm}$. Melville and Chiew equation [10] obtained the equilibrium time as equation 1:

$$
\begin{gathered}
\frac{d_{s t}}{d_{s e}}=\exp \left\{-0.03\left|\frac{U_{c}}{U} L N\left(\frac{t}{t_{e}}\right)\right|^{1.6}\right\}=0.9 \Rightarrow \frac{t_{90}}{t_{e}}=\exp \left(-2.193 \frac{U}{U_{c}}\right) \\
t_{e}=30.89 \frac{D}{U}\left(\frac{U}{U_{c}}-0.4\right)\left(\frac{y_{0}}{D}\right)^{0.25} \quad \frac{y_{0}}{D} \leq 6
\end{gathered}
$$

Which $t_{e}$ : equilibrium time $(\mathrm{hr}), U(\mathrm{~m} / \mathrm{s})$ : flow velocity, $U_{c}(\mathrm{~m} / \mathrm{c})$ : critical velocity in threshold of motion, $D$ : pier diameter, $\mathrm{y}_{0}$ : initial flow depth, $d_{s t}$ : scour depth at the time $t$ and $d_{s e}$ : maximum scour depth. Also $t_{90 \%}$ is the time that $90 \%$ of the scouring occurs in it. By supposing $d_{s t} / d_{s e}=0.9$ and according to flow depth $\left(y_{0}=0.105^{\mathrm{m}}\right)$, mean velocity $\left(U=0.317^{\mathrm{m} / \mathrm{s}}\right)$ and shear velocity $\left(U_{c}=0.338 \mathrm{~m} / \mathrm{s}\right)$, have $t_{e}=44.36^{\mathrm{hr}}$ and $t_{90 \%}=5.77^{\mathrm{hr}}$.

According to obtained time from the equation and witness experiment, all of the experiments have done at 7 hours. However this time was less than 7 hours in types of employed models. Of a ruler that installed on the pier used to measure the scour depth. This depth recorded at first hour in every 10 minutes and at second hours in every 20 minutes and from third hours every 30 minutes in front of the pier. Flow depth was measured by a point gauge having an accuracy of $\pm 0.1 \mathrm{~mm}$. To investigation of the collar effect on the rate of scouring around the bridge pier used from three different sizes of collar, $W / D=1.5,2,2.5$ ( $W$ : length and diameter of square and circular collar respectively) (Fig. 4). According to Dargahi's experiments [11] if the collar thickness to the pier diameter ratio be great, so causes to increasing of the effective diameter of the pier and increasing of scour depth. In this study the plates by $1 \mathrm{~mm}$ thickness was used. Also in three different level were used for the collar positioned, $Z / D=-0.4,0,0.4$ ( $Z$ : distance of collar into the bed surface). 


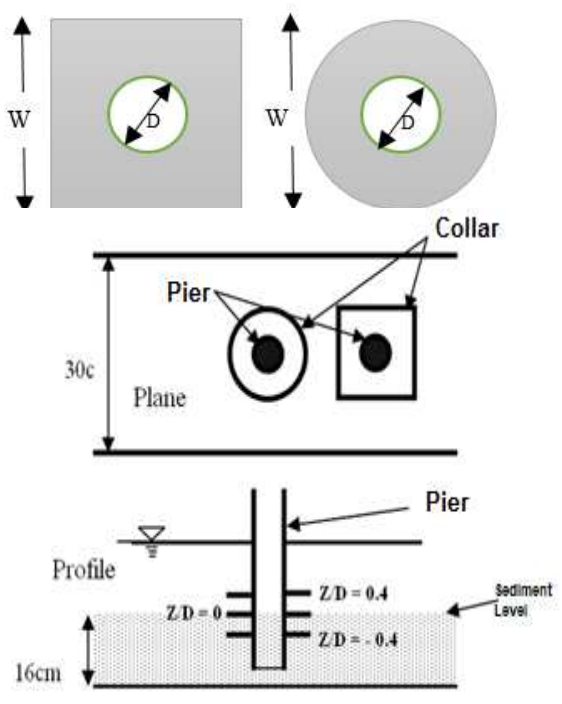

Fig. 4.Square and circular collar

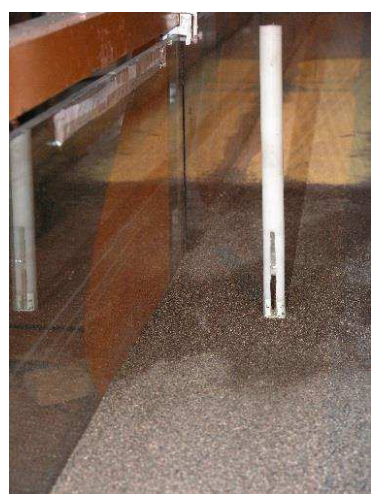

Fig. 5.View of the pier

\section{Results}

\subsubsection{Simple pier (Pier without collar)}

Fig. 6 shows the time development of scouring in simple pier (without collar). This figure shows that after 7 hours, the scour hole reaches approximately to equilibrium. So according to this condition, equilibrium time of scouring was selected $7 \mathrm{hrs}$ for all experiments. In this case, scouring starts from the front side of the pier, concurrent into the pier axis and sediment materials washed from the front side and around the pier and gather as a hill in back of the pier. This hill gradually convey towards downstream. The maximum scour depth was $53 \mathrm{~mm}$ that occurs in front side of the pier and has less than $4 \%$ and $6 \%$ difference with Melville and Chiew [10] and State University of Colorado equations, respectively [12].

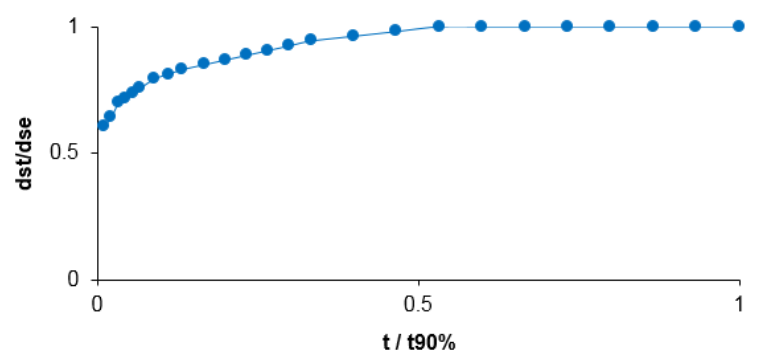

Fig. 6. Time development of scouring in the pier without collar

\subsubsection{Pier with Square collar}

Figs 7 shows the time development of scouring around the pier with square collar in different dimensions $(W / D=1.5,2,2.5)$ and different elevation positions $(Z / D=$ $-0.4,0,0.4)$. The results shows that collar dimension and the installation level are important in reduction of scour depth. The collars that installed above the bed surface had not significant 
effect in scour reduction. It probably is due to create space between the collar and bed surface that causes to formation of the horse-shoe vortex. But when collars installed on or under the bed, the scour depth in front of pier was reduced, it can be by control and reducing the horseshoe vortex force. When collar positioned on the bed it observed that around the collar edges created wakes at first that these wakes developed during the time and increased the scour depth around the pier. When collars are located below (under) the bed elevation, sediment materials above them, are washed immediately by starting the flow. The rate of erosion reduced after reaching the scour hole to collar. This condition shows that collar effects on flow pattern and changes the erosion process. Generally if collar installed lower, the scour reduction percent will be more. But it should contemplate that increasing of collar installation depth causes to increasing of the space above it that has unfavourable effect on the rate of scouring. So we can suppose optimum depth under the bed elevation to collar installation that the scour reaches to its minimum value. Experimental observations showed that when collar is located under the bed elevation, the sediment above the collar washes by the flow immediately but scouring is associated with time delay. This time delay continued until two hours for $2.5 \mathrm{D}$ collar under the bed elevation. Installation of $2.5 \mathrm{D}$ collar under the bed can reduce scour depth approximately $70 \%$. This reduction is up to $20 \%$ and $40 \%$ for $1.5 \mathrm{D}$ and 2D collar, respectively.
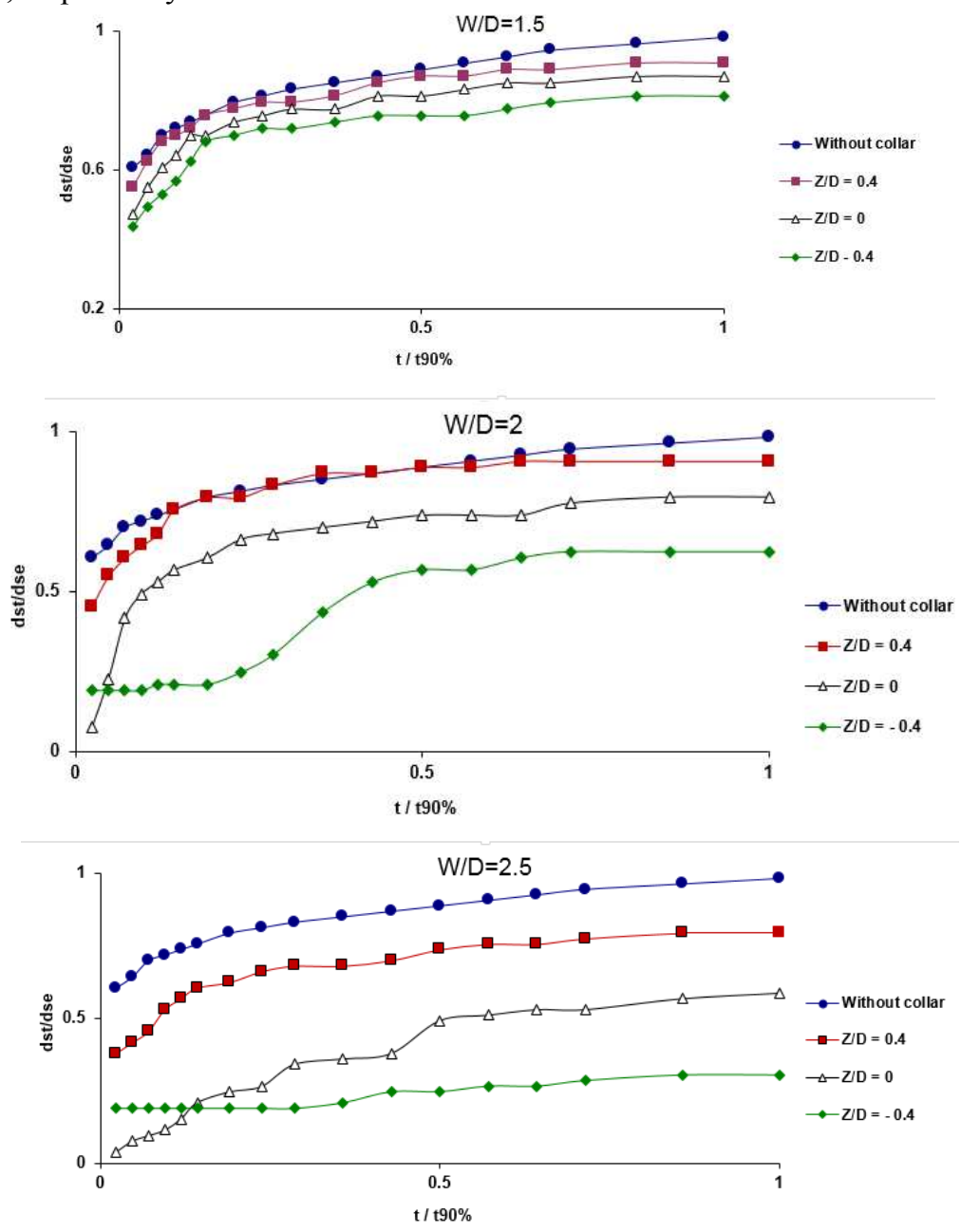

Fig. 7.Time development of scouring in pier with square collar with different W/D 


\subsubsection{Pier with circular collar}

Fig. 8 shows the time development of scouring around of the circular collar in different dimensions $(W / D=1.5,2,2.5)$ and by locating in different elevations $(Z / D=-0.4,0)$ on the pier. Whereas the scour reduction is negligible when the collar is located above the bed surface so the above two elective elevations spotted for locating of the collar. The obtained results about the effect of circular collar in different dimensions showed that whatever the collar be greater and is located on the bed will have more effect on the scour depth. Its reason is that the collar obstructed the down flow and prevented from formation of the strong horseshoe vortex. Whatever the collar location be lower, less flow infiltrates under the collar and makes weaker down flow. The best situation for collar is when the collar is located some deal under the bed surface that in this situation the distance between the collar and river bed washed rapidly and is a part of scour depth. Of other advantages of using of the collar in scouring control is the time delay in rate of scouring that this time delay was one hours by using of $2.5 \mathrm{D}$ circular collar under the bed elevation. Installation of $2.5 \mathrm{D}$ collar under the bed can reduce the scour depth up to $55 \%$. This reduction is $15 \%$ and $24 \%$ for $1.5 \mathrm{D}$ and $2 \mathrm{D}$ collar, respectively.
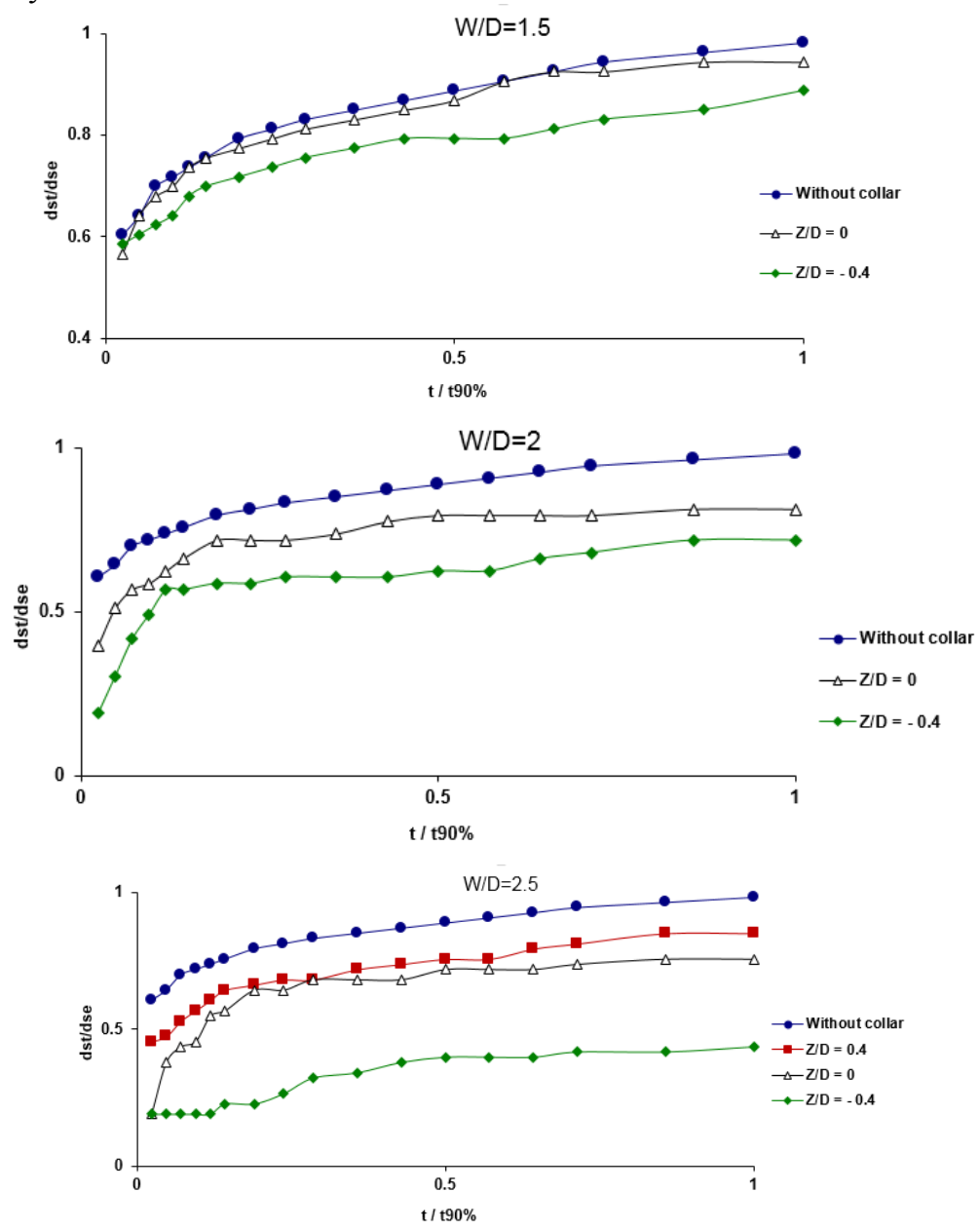

Fig. 8. Time development of scouring in pier with circular collar with different W/D 
According to represented equation by Kumar et al [3] that is applicable only for circular collar that are located on and above the bed, the rate of scour reduction by using of $2 \mathrm{D}$ and $2.5 \mathrm{D}$ collars are $17 \%$ and $25 \%$, respectively. In this research scour reduction percent in order to (for) $2 \mathrm{D}$ and $2.5 \mathrm{D}$ collars by locating on the bed surface are $18 \%$ and $24 \%$, respectively that have a good accordance by Kumar et al [3] equation. The difference between the scour reduction percent can be due to non-uniformity of the bed materials. Also the results of present research by Dargahi's results [11] have a good accordance. Dargahi [11] showed that by locating of circular collar $0.015 \mathrm{y}_{0}$ under the bed surface $\left(\mathrm{y}_{\mathrm{c}} / \mathrm{y}_{0}=-0.015\right)\left(\mathrm{y}_{\mathrm{c}}\right.$ : collar elevation into the bed) the scour depth reduced $50 \%$ upstream the pier.

\subsubsection{Comparison between circular and square collar}

Fig. 9 shows a comparison between the circular and square collar application in cylindrical pier. The results shows that the square collar has more efficiency than the circular collar in reducing of scouring. The geometry and sharp edges of square collar is more effective in scour depth reduction. Also, total area of square collars is more than circular collars, and it can be effective in scour depth reduction. Maximum reduction of scour depth in square and circular collars is $70 \%$ and $57 \%$, respectively. The reduction percent of scour depth by using of circular and square collars have shown in Table 1.

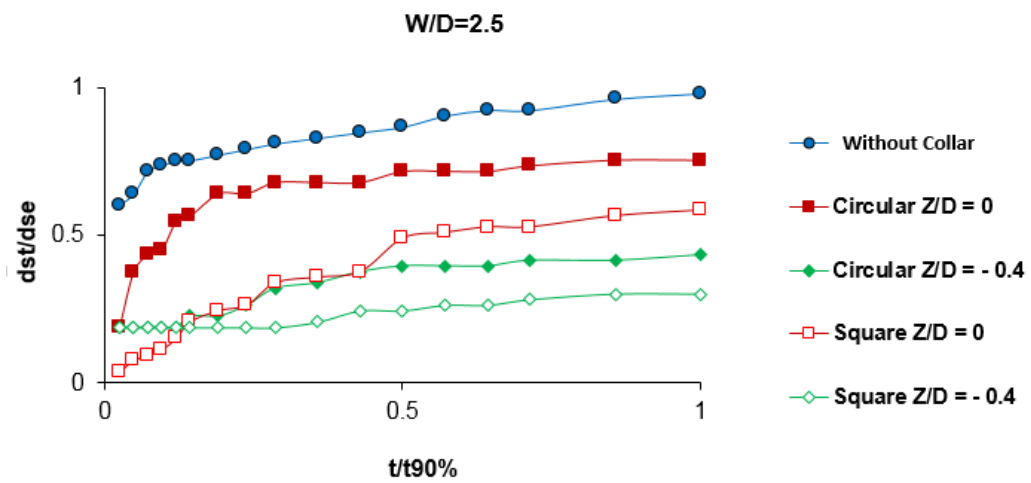

Fig. 9. Time development of scouring for circular and square collars with $\mathrm{W} / \mathrm{D}=2.5$

Table 1.Scour reduction percent into the pier without collar

\begin{tabular}{|c|c|c|c|c|}
\hline Collar Types & Dimension & $\frac{W}{D}=1.5$ & $\frac{W}{D}=2$ & $\frac{W}{D}=2.5$ \\
\hline \multirow{2}{*}{ Circular } & Location & 5.6 & 18.8 & 24.5 \\
\cline { 2 - 5 } & Onder the bed $(\mathrm{Z} / \mathrm{D}=0)$ & 11.3 & 28.3 & $\mathbf{5 6 . 6}$ \\
\hline \multirow{2}{*}{ Square } & On the bed $(\mathrm{Z} / \mathrm{D}=-0.4)$ & 13.2 & 20.75 & 41.5 \\
\cline { 2 - 5 }$=0)$ & Under the bed $(\mathrm{Z} / \mathrm{D}=-0.4)$ & 18.8 & 37.7 & $\mathbf{7 0}$ \\
\hline
\end{tabular}

\section{Conclusion}

In this research two types of square and circular collars was examined to reduce the local scour in a single cylindrical pier in different dimensions and different elevations. The results showed that generally using of the collar is effective for reduction of scouring. Also using of 
the collar under the bed surface is more effective compared the other elevations. Also increasing of dimension has more effect on the scour reduction. Also this research showed that the square collar is more effective in scour depth reduction. This type of collar can reduce the scouring depth about $70 \%$.

\section{References}

1. B. W. Melville, and S. E. Coleman, Bridge Scour, Water Res. Pub., LLC, Colorado, U.S.A., 550. (2000).

2. M.B.,Mashahir, A.R. Zarrati, and A.R. Rezayi, Time Development of Scouring around a Bridge Pier Protected by Collar, $2^{\text {nd }}$ Int. Conf. on Scour and Erosion, ICSE-2, Singapore. (2004).

3. V. Kumar, K. Raja, N. Vittal. Reduction of local scour around bridge piers using slots and collars, piers. J. Hydr. Eng., 125 12, 1302-1305. (1999)

4. A.R. Zarrati, M. Nazariha, and M.B. Mashahir, Reduction of Local Scour in the vicinity of Bridge Pier groups using Collars and Riprap, J. of Hyd. Eng., 132, 2, 154-162. (2006).

5. M.A. Moncada, J. Aguirre, J.C. Bolivar, E.J. Flores. Scour protection of circular bridge piers with collars and slots. J. Hydr. Res. 47, 1,119-126. (2009)

6. L. Brandimart, P. Paron, G. Di Baldassarre, Bridge pier scour: a review of processes, measurements and estimates, Envir. Eng. and Manag. J., 11, 5, 975-989(2012).

7. N.Karimi, M. Heidarnejad, A. Masjedi, Scour depth at inclined bridge piers along a straight path: A laboratory study, Eng. Sci. and Tech., an Intro. J., 20, 4, 13021307(2017)

8. Y.M. Chiew, B.W. Mellville. Local Scour around Bridge Piers. J. Hydr. Res., 25, 1,1526, (1987).

9. A. Raudkivi, R. Ettema. Clear-water scour at cylindrical piers. J. Hydr. Eng. 109, 3,338350. (1983).

10. W.Melville, Y.Chiew, Time scale for local scour at bridge piers. J. Hydr. Eng. 125,1, 59-65. (1999)

11. B. Dargahi ,Controlling Mechanism of local scouring". J. Hydr. Eng.116,10,1197-1214. (1990).

12. R. Ettema, B.W. Melville, and B. Barkdoll, Scale effect in pier-scour experiments. J. Hydr. Eng., 124, 6 639-642 (1998). 